\title{
Evidence for non-neutralizing autoantibodies against IL-10 signalling components in patients with inflammatory bowel disease
}

\author{
Natalie Frede ${ }^{1}$, Erik-Oliver Glocker²,3, Jennifer Wanders ${ }^{2}$, Karin R Engelhardt ${ }^{1,2}$, Wolfgang Kreisel ${ }^{4}$, \\ Frank M Ruemmele 5 and Bodo Grimbacher ${ }^{1,2^{*}}$
}

\begin{abstract}
Background: Inflammatory bowel disease constitutes a heterogeneous group of conditions, whose aetiology is only partly understood. The prevailing hypothesis on its pathogenesis is that IBD is the result of an inadequate immune response to the resident bacterial flora of the intestine. An autoimmune background, however, has been discussed since the 1950s. Lately, it has been shown that failures in interleukin-10 (IL-10) signalling due to IL-10and IL-10 receptor (IL-10R) mutations result in IBD. Our study aimed at investigating the existence of inhibitory autoantibodies against IL-10 and IL-10R in IBD patients capable of down-modulating IL-10 signalling thereby mimicking IL-10 or IL-10R deficiency.
\end{abstract}

Results: Thirteen IBD patients had IgG autoantibodies against IL-10, IL-10RA and/or IL-10RB, and three patients had IgA autoantibodies against IL-10. However, the absolute OD values of the serum antibodies measured by ELISA were Iow, there was overall no significant difference between patients and controls, and positive sera had no neutralizing activity.

Conclusion: No evidence for an involvement of autoantibodies against IL-10 or IL-10R in the pathogenesis of inflammatory bowel disease could be established.

Keywords: Inflammatory bowel disease, Autoantibodies, Autoimmunity, Interleukin-10, IL-10 receptor

\section{Background}

Inflammatory bowel disease (IBD) includes Crohn's disease, ulcerative colitis and indeterminate colitis and is characterized by a chronic and relapsing inflammation of the small or large intestine, abdominal pain, diarrhea, bleeding and malabsorption. With a prevalence of up to 450 per 100,000 inhabitants in the UK, IBD constitutes a common inflammatory condition; hence, the impact of associated morbidity and mortality is estimated to be substantial [1].

IBD is considered as the result of an excessive and inadequate immune response to commensals of the intestine, defining IBD as a pro-inflammatory disorder [2]. In addition, at least in a subgroup of patients, IBD might also

\footnotetext{
* Correspondence: bodo.grimbacher@uniklinik-freiburg.de

${ }^{1}$ Centre of Chronic Immunodeficiency, University Medical Centre Freiburg, Engesser Straße 4, 79108 Freiburg, Germany

${ }^{2}$ Department of Immunology, Division of Infection and Immunity, University

College London, Royal Free Hospital, London, UK

Full list of author information is available at the end of the article
}

be an immunodeficiency due to impaired release of proinflammatory cytokines by macrophages [3,4]. This hypothesis is supported by several primary immunodeficiencies that are characterized by IBD-like phenotypes such as IPEX syndrome, XIAP deficiency, and NEMO deficiency [5-7]. IL-10- and IL-10R deficiencies add to these disorders: affected patients manifest with severe early-onset enterocolitis which shows a dramatic and life-threatening progress [8-10]. The latter underscore the necessity of IL10 to control inflammation and keep our immune system in balance [11-13].

For a long time, an autoimmune background has been suggested for IBD, and antibodies against numerous auto-antigens have been detected [14-18]. In 2009, Ebert et al. described autoantibodies against various cytokines in IBD patients leading to a state of relative deficiency of IL2, TGF- $\beta$ and IL-10 [19]. Given the relevance of IL-10 as the key immunomodulatory factor of the human immune system, neutralizing autoantibodies against IL-10

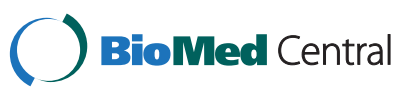


or IL-10R might significantly impair IL-10 signalling and contribute to the severity of IBD.

In this study, we aimed to investigate the existence of autoantibodies binding to IL-10 or to the IL-10R, thus abrogating IL-10 signalling and mimicking a state of IL-10 deficiency. Here, we present the results of a screening for autoantibodies of the IgG and IgA isotype, putatively directed against IL-10 signalling components in 52 IBD patients.

\section{Results and discussion}

Antibodies against IL-10

\section{Antibodies of the IgG isotype}

Sera of 20 healthy donors as well as 52 IBD patients were subjected to ELISA testing in search of anti-IL10 IgG antibodies. Upon testing, eight out of 52 IBD patients (15\%) showed OD values above a cut-off of $\mu+3 \mathrm{SD}$ (Figure 1A). Data were analyzed by t-test, comparing the Crohn's disease (CD) and ulcerative colitis (UC) groups both to the healthy control group. We found the CD group to exhibit significantly elevated levels of anti-IL-10 IgG antibodies, whereas the $\mathrm{UC}$ group testing resulted in a non-significant $\mathrm{p}$-value $(p=0.41)$. In our cohort, $18 \%$ of CD patients $(7 / 38)$ had anti-IL-10 autoantibodies; this replicates the results of Ebert et al. [19], who found 17\% of CD patients to have anti-IL-10 IgG autoantibodies in the serum, thus validating our results in spite of a small sample size.

However, it has also been reported that anti-IL-10 antibodies may be present in high titers in healthy blood donors $[20,21]$, and anti-cytokine autoantibodies are believed to occur ubiquitously in healthy individuals [22]. Furthermore, in contrast to other diseases with neutralizing anti-cytokine autoantibodies [23,24], but similar to the anti-IL-10 antibodies found by Ebert et al. [19], the increase in OD values was not striking in our patients.

\section{Antibodies of the IgA isotype}

Previous studies only reported on IgG anti-IL-10 antibodies in their populations. However, IgA constitutes a crucial element of mucosal immunity and is the most abundant immunoglobulin in the gut. Thus, its putative role in IBD has often been speculated upon and early reports implied that abnormal IgA function may play a role in the pathogenesis of IBD [25].

We therefore extended our search for the detection of anti-IL-10 autoantibodies of the IgA isotype. The sera of $52 \mathrm{IBD}$ patients, i.e. $38 \mathrm{CD}$ and $14 \mathrm{UC}$ patients, and 10 randomly chosen healthy donors were probed.

In three patients ( $2 \mathrm{CD}$ and $1 \mathrm{UC}$ ), elevated ODs were found for anti-IL-10 IgA autoantibodies, while means of all groups were not significantly different (Figure 1B).

The number of patients with anti-IL-10 IgA autoantibodies might however, be underestimated with the chosen assay. Probing of serum samples may not be the best method to detect autoantibodies of the IgA isotype, as antibodies may accumulate in the inflamed tissue of the gut so that concentrations significantly higher than in the serum may be reached. Also, while IgA makes up two thirds of the produced antibodies, it is mostly secreted so that it constitutes only $15 \%$ of the immunoglobulins present in human serum. Additionally, it is possible that the titre of autoantibodies fluctuates over time in a given patient.

In conclusion, our results suggest that single IBD patients might produce class IgA autoantibodies against IL-10. Yet, the significance of these antibodies is unclear.

\section{Antibodies against the IL-10R Antibodies of the IgG isotype}

In order to investigate whether IBD patients might produce IgG antibodies binding to the IL-10 receptor, sera of 50 healthy blood donors and 52 IBD patients were analysed by ELISA for binding to either recombinant IL10R1 or IL-10R2 (Figure 2A).
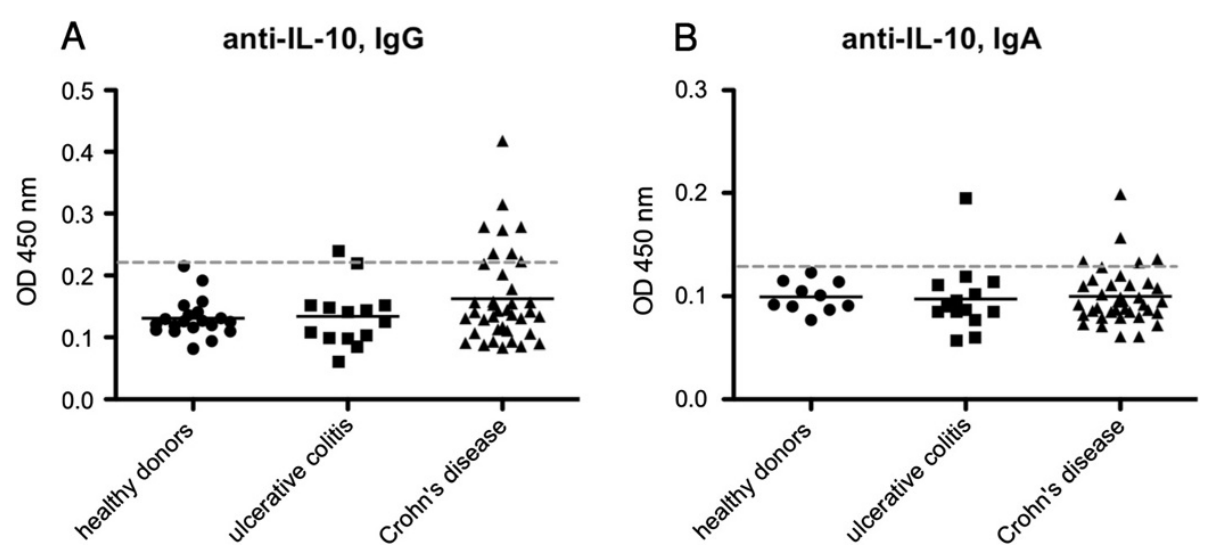

Figure 1 Autoantibodies against IL-10. Serum samples of patients suffering from inflammatory bowel disease were tested for anti-IL-10 Immunoglobulin G (A) and Immunoglobulin A (B) by ELISA. The dotted line represents the cut-off, whereas means are depicted as solid lines. 

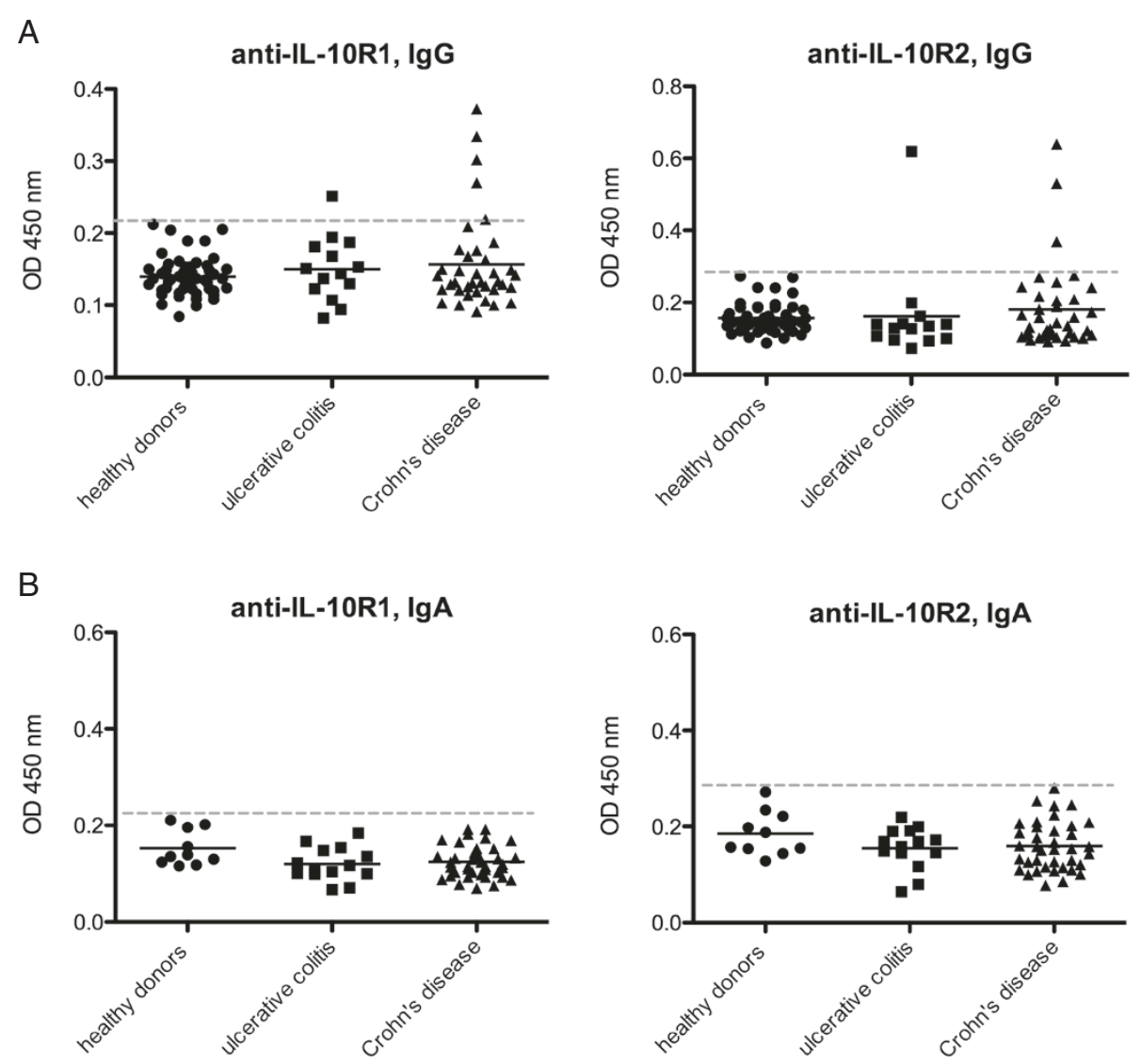

Figure 2 Autoantibodies against the IL-10 receptor. Serum samples of IBD patients and healthy donors were tested by ELISA for IgG (A) and IgA (B) antibodies binding to IL-10R1 and IL-10R2. The dotted line represents the cut-off, whereas means are depicted as solid lines.

Neither for anti-IL-10R1 nor for anti-IL-10R2 significant differences between means of IBD patients and healthy blood donors could be detected; statistical analysis failed to reach the significance level of $p<0.05$. Stratifying patients according to the site of disease manifestation did not change the results (Additional file 1: Figure S1).

However, few patients proved to have significantly elevated ODs of up to 4 times the mean suggesting that some IBD patients do produce autoantibodies against IL-10R1 or IL-10R2. In the CD group, three out of 38 patients (8\%) tested for anti-IL-10R2 had values that were higher than any value measured in the healthy donor group (method after [19]), compared to one out of 14 patients (7\%) in the UC group. Regarding anti-IL-10R1, four out of $38 \mathrm{CD}$ patients (11\%) and one out of 14 UC patients (7\%) had elevated values.

Another method to determine a cut-off for positive values is to calculate $\mu+2 \mathrm{SD}$ or $\mu+3 \mathrm{SD}$, i.e. the mean of a healthy donor population and addition of 2 or 3 standard deviations. Using the $\mu+3$ SD method on our samples provided exactly the same results as the method described above, i.e. one $\mathrm{UC}$ and four $\mathrm{CD}$ patients were above the calculated cut-off for anti-IL-10R1 and one UC and three
CD patients for anti-IL-10R2. Thus, IgG autoantibodies against the IL-10R seem to be produced by a nonsignificant number of patients in our cohort.

\section{Antibodies of the IgA isotype}

The sera of 52 IBD patients, i.e. $38 \mathrm{CD}$ and $14 \mathrm{UC}$ patients, and 10 randomly chosen healthy donors were probed for anti-IL-10R autoantibodies of the IgA isotype.

No increased absorption values were found for antiIL-10R1 and anti-IL-10R2 IgA autoantibodies in patients' sera (Figure 2B), indicating that neither Crohn's disease nor ulcerative colitis patients from our cohort produce IgA autoantibodies against the IL-10R.

\section{Limitations of the ELISA technology as a screening method}

Recombinant proteins, such as the rIL-10R1 and rIL10R2, may have different epitopes than the in vivo receptor on the cell surface. Hence, antibodies binding to the rIL-10R might in fact not recognize the IL-10 receptor in vivo and vice versa. Furthermore, it is well known that surface-protein interactions, e.g. between the ELISA plate and the recombinant protein, can induce conformational changes and therefore subsequently inhibit or facilitate 
antibody binding. In order to address these limitations, a functional assay was developed to evaluate the ELISA results.

\section{Functional test for neutralizing activity of anti-IL-10R antibodies}

To assess whether the detected IL-10R autoantibodies have functional consequences, their impact on STAT3 phosphorylation, a key event in IL-10 signalling, was determined.

Sera of UC and CD patients $(n=21)$ were compared with serum of a healthy donor control. A commercial antibody directed against IL-10R2 (R\&D, UK) was used as a positive control. Analysis of STAT3 phosphorylation upon IL-10 stimulation of PBMCs pre-incubated with a 1:10 dilution of serum failed to demonstrate a significant reduction of ODs, and therefore STAT3 phosphorylation, in the IBD patient cohorts (Figure 3). There were no significant differences between ELISA-positive and -negative samples or between UC and CD samples.

In conclusion, we could not find evidence for the functional relevance of autoantibodies against the IL-10 receptor. Neither did we find any evidence for the existence of autoantibodies, which were not detected by ELISA but had a sufficiently high titer to significantly reduce downstream signalling.

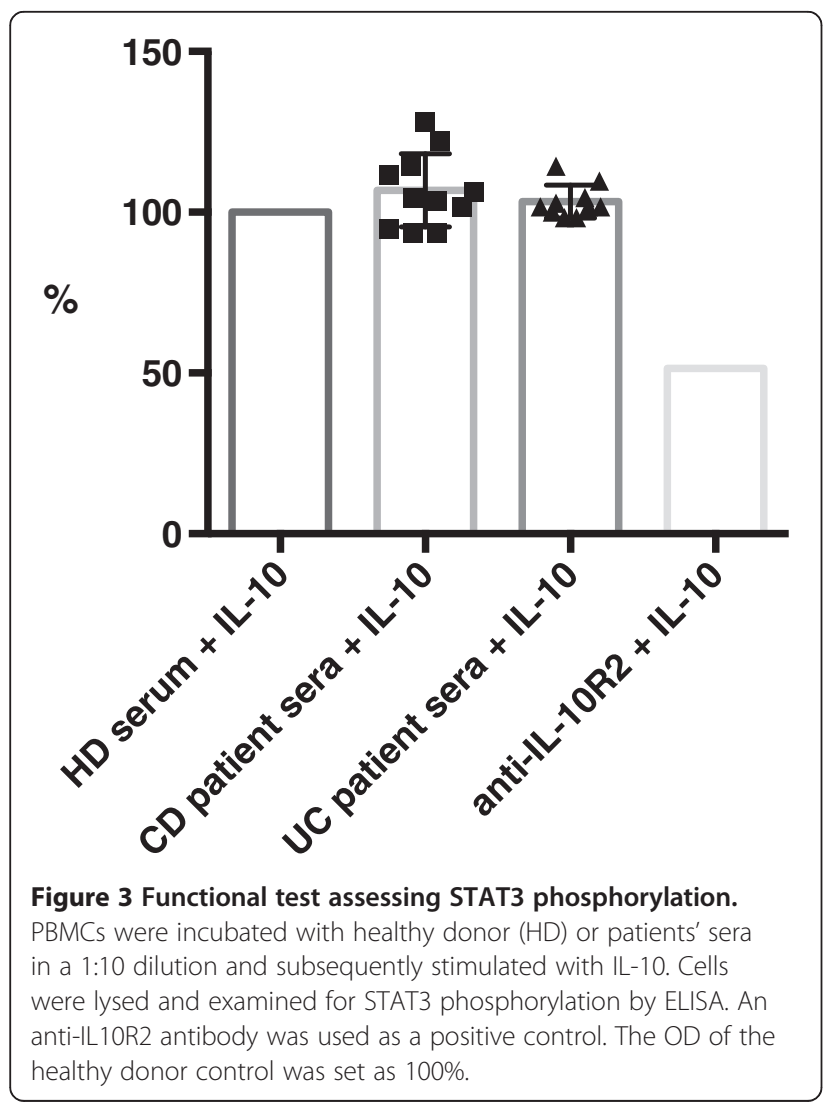

\section{Single and multiple positives}

In total, 13 of 52 patients (25\%) were found to have autoantibodies against IL-10 or the IL-10R subunits IL10R1 and IL-10R2 (Table 1).

Whereas eight patients had antibodies against either IL-10 or one subunit of the IL-10R alone, sera of four patients were double positive for antibodies against IL10 and IL-10R; one patient had serum triple positive for anti-IL-10, anti-IL-10R1 and anti-IL-10R2 antibodies. The latter patients might generally have an increased auto-immune status with possibly other autoantibodies in the serum as well. This, the low absolute OD values, and the fact that the IL-10R autoantibodies had no neutralizing activity, suggest that the autoantibodies might not be of overall significance.

\section{Conclusion}

Our results do not provide sufficient evidence to postulate a general autoimmune disruption of IL-10 signalling in the pathogenesis of IBD.

Overall, no significant difference could be detected between IBD patients and healthy controls, with only singleton patients having been tested positive for autoantibodies against IL-10 and/or IL-10R in serum. Furthermore, the absolute OD values of detected autoantibodies were low with only a minor increase above the cut-off level in most positive patients. Most significantly, the sera positive for anti-IL-10R antibodies failed to show neutralizing activity in a functional test, further supporting the assumption that the detected antibodies are of little significance. Lastly, the finding that some patients were double or even triple positive for autoantibodies against IL-10 and IL-10R might reflect a low level autoimmune state with a broader range of autoantibodies with unknown significance.

While the understanding of the molecular mechanisms underlying inflammatory bowel disease gradually increases, further research needs to be conducted in order to identify the exact immune processes contributing to the complex pathogenesis of IBD. Genetic and functional data suggest IBD might be even more heterogeneous than initially expected [26,27]. Only after these

Table 1 Patients single or multiple positive for antiautobodies against the IL-10 signalling pathway

\begin{tabular}{|c|c|c|c|c|c|c|}
\hline $\begin{array}{c}N^{\circ} \text { of patients } \\
\text { with antibodies } \\
\text { against: }\end{array}$ & $\begin{array}{l}\text { IL- } \\
10\end{array}$ & $\begin{array}{l}\text { IL- } \\
\text { 10R1 }\end{array}$ & $\begin{array}{c}\text { IL- } \\
\text { 10R2 }\end{array}$ & $\begin{array}{l}\text { IL-10 + } \\
\text { IL-10R1 }\end{array}$ & $\begin{array}{l}\text { IL-10 + } \\
\text { IL-10R2 }\end{array}$ & $\begin{array}{c}\text { IL-10 + IL- } \\
\text { 10R1 + IL-10R2 }\end{array}$ \\
\hline $\lg G$ & 3 & 2 & 1 & 1 & 2 & 1 \\
\hline $\lg A$ & 2 & - & - & $1^{1}$ & - & - \\
\hline $\begin{array}{c}\text { Total } n^{\circ} \text { of } \\
\text { patients }\end{array}$ & 5 & 2 & 1 & 2 & 2 & 1 \\
\hline
\end{tabular}

${ }^{1}$ This patient had anti-IL-10 antibodies of the IgG and IgA isotype. Thirteen patients had autoantibodies affecting the IL-10 signalling pathway. Eight patients had antibodies against a single protein, and five patients had antibodies against multiple components. 
topics have been addressed, more specific targeted therapies can be developed.

\section{Methods}

\section{Patient cohorts}

Patients' serum samples $(n=52)$ were collected from IBD clinics in Freiburg and Paris, Necker Enfants Malades. Thirty-eight patients had Crohn's disease and 14 had ulcerative colitis. Patients were diagnosed according to the Consensus of the European Crohn's and Colitis Organisation (ECCO) $[28,29]$ or the Porto-criteria and classified according to the Paris classification [30,31]. Samples were aliquoted upon receipt. All patients gave their informed consent; approval was granted by the National Research Ethics Service Committee London - Hampstead, formerly North West London REC 2/ Royal Free Hospital and Medical School REC, London, UK (Ref. 08/H0720/46 for healthy donors and 04/Q0501/119 for patients).

\section{Enzyme-linked immunosorbent assay (ELISA)}

Flat-bottomed microtitre plates (Nunc-Immuno Plate Maxisorp Surface) were coated with recombinant IL10R1 (R\&D Systems) or IL-10R2 (Abnova) at a concentration of $2 \mu \mathrm{g} / \mathrm{ml}$ or with $0.5 \mu \mathrm{g} / \mathrm{ml} \mathrm{IL-10} \mathrm{diluted} \mathrm{in}$ carbonate buffer, $\mathrm{pH} 9.5$ and incubated overnight at $4{ }^{\circ} \mathrm{C}$. The plates were washed with PBS-Tween $(0.05 \%)$. Free binding sites on the plate were blocked with $300 \mu \mathrm{l} 1 \%$ bovine serum albumin (BSA) (Sigma, US) for an incubation time of $1 \mathrm{~h}$.

Human sera were added in a 1:200 dilution. Following a $2 \mathrm{~h}$ incubation period the plates were washed 5 times. The secondary antibody was added and incubated for $1 \mathrm{~h}$. After washing, $100 \mu \mathrm{l}$ of substrate TMB were added to each well. Colour development was monitored and $50 \mu \mathrm{l}$ of $2 \mathrm{M}$ sulphuric acid were added to stop the reaction. $\mathrm{Ab}$ sorption was determined in an ELISA reader at $450 \mathrm{~nm}$.

\section{STAT3 phosphorylation assay}

Peripheral blood mononuclear cells (PBMCs) were isolated using the Ficoll technique and then washed in PBS (Sigma, US). $10^{5}$ PBMCs were resuspended in $180 \mu \mathrm{L}$ Opti-Mem I serum-free medium (Invitrogen, UK), added in 96-well plates and then pre-incubated for one hour with $20 \mu \mathrm{L}$ neat or 1:10 diluted serum from anti-IL-10R auto-antibody positive patients. Cells were then stimulated with $5 \mathrm{ng}$ IL10 (R\&D, UK) for 10 minutes, lysed and examined for STAT3 phosphorylation by ELISA (Cell signaling, UK) according to manufacturer's instructions.

\section{Additional file}

Additional file 1: Figure S1. Subgroup analysis of Crohn's disease patients from Paris. Crohn's disease patients were subgrouped for disease localisation after their sera were tested for $\lg G(A)$ and $\lg A(B)$ autoantibodies against IL-10 and IgG autoantibodies against the IL-10 receptor (C) by ELISA. The dotted line represents the cut-off, whereas means are depicted as solid lines.

\section{Abbreviations}

IBD: Inflammatory bowel disease; CD: Crohn's disease; UC: Ulcerative colitis; IL-10: Interleukin 10; IL-10R: IL-10 receptor; APECED: Autoimmune polyendocrinopathy-candidiasis-ectodermal dystrophy; CMC: Chronic mucocutaneous candidiasis.

\section{Competing interests}

The authors declare that they have no competing interests.

\section{Authors' contributions}

NF carried out the ELISA and STAT3 phosphorylation assays. EOG designed the study and drafted the manuscript. JB carried out ELISA assays. KRE participated in the design of the study and helped to draft and revise the manuscript. WK diagnosed patients and collected serum samples. FMR diagnosed patients, collected serum samples and did the subgroup analysis of Crohn's disease patients from Paris. BG conceived of the study, and participated in its design and coordination and helped to write the manuscript. All authors read and approved the final manuscript.

\section{Acknowledgements}

This work has been supported by the EC Marie-Curie Grant MEXT-CT2006-042316, as well as by funds from the EU 7th framework programme (FP7 2007-2013 No. 223293 and FP7 2007-2013 EURO-PADnet HEALTH-F22008-201549), by the German Federal Ministry of Education and Research (BMBF 01 EO 0803) and by Marie Curie Actions CIG (294253, EOG). The authors are responsible for the contents of this publication.

The article processing charge was funded by the open access publication fund of the Albert Ludwigs University Freiburg.

\section{Author details}

${ }^{1}$ Centre of Chronic Immunodeficiency, University Medical Centre Freiburg, Engesser Straße 4, 79108 Freiburg, Germany. ${ }^{2}$ Department of Immunology, Division of Infection and Immunity, University College London, Royal Free Hospital, London, UK. Institute of Medical Microbiology and Hygiene, University of Freiburg, Freiburg, Germany. ${ }^{4}$ Department of Gastroenterology, Hepatology and Endocrinology, University Hospital Freiburg, Freiburg, Germany. ${ }^{5}$ Université Paris-Descartes, Sorbonne, Paris Cité. INSERM U989, Assistance Publique-Hopitaux de Paris, Hôpital Necker Enfants Malades, Service de Gastroentérologie pédiatrique, Paris, France.

Received: 3 July 2013 Accepted: 6 February 2014 Published: 28 February 2014

\section{References}

1. Baumgart DC, Sandborn WJ: Inflammatory bowel disease: clinical aspects and established and evolving therapies. Lancet 2007, 369:1641-1657.

2. Baumgart DC, Carding SR: Inflammatory bowel disease: cause and immunobiology. Lancet 2007, 369:1627-1640.

3. Hayee B, Rahman FZ, Sewell G, Smith AM, Segal AW: Crohn's disease as an immunodeficiency. Expert Rev Clin Immunol 2010, 6:585-596.

4. Smith AM, Rahman FZ, Hayee B, Graham SJ, Marks DJ, Sewell GW, Palmer CD, Wilde J, Foxwell BM, Gloger IS, Sweeting T, Marsh M, Walker AP, Bloom SL, Segal AW: Disordered macrophage cytokine secretion underlies impaired acute inflammation and bacterial clearance in Crohn's disease. J Exp Med 2009, 206:1883-1897.

5. Cheng LE, Kanwar B, Tcheurekdjian H, Grenert JP, Muskat M, Heyman MB, McCune JM, Wara DW: Persistent systemic inflammation and atypical enterocolitis in patients with NEMO syndrome. Clin Immunol 2009, 132:124-131.

6. Pachlopnik SJ, Canioni D, Moshous D, Touzot F, Mahlaoui N, Hauck F, Kanegane H, Lopez-Granados E, Mejstrikova E, Pellier I, Galicier L, Galambrun C, Barlogis V, Bordigoni P, Fourmaintraux A, Hamidou M, Dabadie A, Le DF, Haerynck F, Ouachee-Chardin M, Rohrlich P, Stephan JL, Lenoir C, Rigaud S, Lambert N, Milili M, Schiff C, Chapel H, Picard C, de Saint BG, Blanche S, Fischer A, Latour S: Clinical similarities and differences of patients with 
X-linked lymphoproliferative syndrome type 1 (XLP-1/SAP deficiency) versus type 2 (XLP-2/XIAP deficiency). Blood 2011, 117:1522-1529.

7. van der Vliet HJ, Nieuwenhuis EE: IPEX as a result of mutations in FOXP3. Clin Dev Immunol 2007, 2007:89017.

8. Begue B, Verdier J, Rieux-Laucat F, Goulet O, Morali A, Canioni D, Hugot JP, Daussy C, Verkarre V, Pigneur B, Fischer A, Klein C, Cerf-Bensussan N, Ruemmele FM: Defective IL-10 signaling defining a subgroup of patients with inflammatory bowel disease. Am J Gastroenterol 2011, 106:1544-1555.

9. Glocker EO, Kotlarz D, Boztug K, Gertz EM, Schaffer AA, Noyan F, Perro M, Diestelhorst J, Allroth A, Murugan D, Hatscher N, Pfeifer D, Sykora KW, Sauer M, Kreipe H, Lacher M, Nustede R, Woellner C, Baumann U, Salzer U, Koletzko S, Shah N, Segal AW, Sauerbrey A, Buderus S, Snapper SB, Grimbacher B, Klein C: Inflammatory bowel disease and mutations affecting the interleukin-10 receptor. N Engl J Med 2009, 361:2033-2045.

10. Glocker EO, Frede N, Perro M, Sebire N, Elawad M, Shah N, Grimbacher B: Infant colitis-it's in the genes. Lancet 2010, 376:1272.

11. de Waal MR, Abrams J, Bennett B, Figdor CG, de Vries JE: Interleukin 10 (IL-10) inhibits cytokine synthesis by human monocytes: an autoregulatory role of IL-10 produced by monocytes. J Exp Med 1991, 174:1209-1220.

12. Moore KW, de Waal MR, Coffman RL, O'Garra A: Interleukin-10 and the interleukin-10 receptor. Annu Rev Immunol 2001, 19:683-765.

13. Williams LM, Ricchetti G, Sarma U, Smallie T, Foxwell BM: Interleukin-10 suppression of myeloid cell activation-a continuing puzzle. Immunology 2004, 113:281-292.

14. Broberger O, Perlmann P: Autoantibodies in human ulcerative colitis. J Exp Med 1959, 110:657-674.

15. Das KM, Dasqupta A, Mandal A, Geng X: Autoimmunity to cytoskeletal protein tropomyosin. A clue to the pathogenetic mechanism for ulcerative colitis. J Immunol 1993, 150:2487-2493.

16. Lundgren BA, Rorsman F, Portela-Gomes GM, Grimelius L, Ekdahl KN, Nilsson B, Ekwall O: Identification of complement $\mathrm{C} 3$ as an autoantigen in inflammatory bowel disease. Eur J Gastroenterol Hepatol 2010, 22:429-436.

17. Rahbar A, Bostrom L, Soderberg-Naucler C: Detection of cytotoxic CD13specific autoantibodies in sera from patients with ulcerative colitis and Crohn's disease. J Autoimmun 2006, 26:155-164.

18. Roggenbuck D, Hausdorf G, Martinez-Gamboa L, Reinhold D, Buttner T, Jungblut PR, Porstmann T, Laass MW, Henker J, Buning C, Feist E, Conrad K: Identification of GP2, the major zymogen granule membrane glycoprotein, as the autoantigen of pancreatic antibodies in Crohn's disease. Gut 2009, 58:1620-1628

19. Ebert EC, Panja A, Das KM, Praveen R, Geng X, Rezac C, Bajpai M: Patients with inflammatory bowel disease may have a transforming growth factor-beta-, interleukin (IL)-2- or IL-10-deficient state induced by intrinsic neutralizing antibodies. Clin Exp Immunol 2009, 155:65-71.

20. de Lemos RC, Galle P, Svenson M, Pedersen BK, Hansen MB: Preparation and validation of radio iodinated recombinant human IL-10 for the measurement of natural human antibodies against IL-10. J Immunol Methods 2009, 350:46-53.

21. de Lemos RC, Galle P, Pedersen BK, Hansen MB: A state of acquired IL-10 deficiency in $0.4 \%$ of Danish blood donors. Cytokine 2010, 51:286-293.

22. Watanabe M, Uchida K, Nakagaki K, Kanazawa H, Trapnell BC, Hoshino Y, Kagamu H, Yoshizawa H, Keicho N, Goto H, Nakata K: Anti-cytokine autoantibodies are ubiquitous in healthy individuals. FEBS Lett 2007, 581:2017-2021.

23. Doffinger R, Helbert MR, Barcenas-Morales G, Yang K, Dupuis S, Ceron-Gutierrez L, Espitia-Pinzon C, Barnes N, Bothamley G, Casanova JL, Longhurst HJ, Kumararatne DS: Autoantibodies to interferon-gamma in a patient with selective susceptibility to mycobacterial infection and organ-specific autoimmunity. Clin Infect Dis 2004, 38:e10-e14.

24. Kisand K, Boe Wolff AS, Podkrajsek KT, Tserel L, Link M, Kisand KV, Ersvaer E, Perheentupa J, Erichsen MM, Bratanic N, Meloni A, Cetani F, Perniola R, Ergun-Longmire B, Maclaren N, Krohn KJ, Pura M, Schalke B, Strobel P, Leite MI, Battelino T, Husebye ES, Peterson P, Willcox N, Meager A: Chronic mucocutaneous candidiasis in APECED or thymoma patients correlates with autoimmunity to Th17-associated cytokines. J Exp Med 2010, 207:299-308.

25. Holdstock G, Ershler WB, Krawitt EL: Defective lymphocyte IgA production in inflammatory bowel disease. Clin Immunol Immunopathol 1982, 24:47-54.

26. Anderson CA, Boucher G, Lees CW, Franke A, D'Amato M, Taylor KD, Lee JC, Goyette P, Imielinski M, Latiano A, Lagace C, Scott R, Amininejad L,
Bumpstead S, Baidoo L, Baldassano RN, Barclay M, Bayless TM, Brand S, Buning C, Colombel JF, Denson LA, De Vos M, Dubinsky M, Edwards C, Ellinghaus D, Fehrmann RS, Floyd JA, Florin T, Franchimont D, et al: Meta-analysis identifies 29 additional ulcerative colitis risk loci, increasing the number of confirmed associations to 47. Nat Genet 2011, 43:246-252.

27. Van Limbergen J, Wilson DC, Satsangi J: The genetics of Crohn's disease. Annu Rev Genomics Hum Genet 2009, 10:89-116.

28. Stange EF, Travis SP, Vermeire S, Reinisch W, Geboes K, Barakauskiene A, Feakins R, Flejou JF, Herfarth H, Hommes DW, Kupcinskas L, Lakatos PL, Mantzaris GJ, Schreiber S, Villanacci V, Warren BF: European evidencebased Consensus on the diagnosis and management of ulcerative colitis: definitions and diagnosis. J Crohns Colitis 2008, 2:1-23.

29. Van Assche G, Dignass A, Panes J, Beaugerie L, Karagiannis J, Allez M, Ochsenkuhn T, Orchard T, Rogler G, Louis E, Kupcinskas L, Mantzaris G, Travis S, Stange E: The second European evidence-based Consensus on the diagnosis and management of Crohn's disease: definitions and diagnosis. J Crohns Colitis 2010, 4:7-27.

30. Working IBD: Group of the European Society for Paediatric Gastroenterology, Hepatology and Nutrition. Inflammatory bowel disease in children and adolescents: recommendations for diagnosis-the Porto criteria. J Pediatr Gastroenterol Nutr 2005, 41:1-7.

31. Levine A, Griffiths A, Markowitz J, Wilson DC, Turner D, Russell RK, Fell J, Ruemmele FM, Walters T, Sherlock M, Dubinsky M, Hyams JS: Pediatric modification of the Montreal classification for inflammatory bowel disease: the Paris classification. Inflamm Bowel Dis 2011, 17:1314-1321.

doi:10.1186/1471-2172-15-10

Cite this article as: Frede et al: Evidence for non-neutralizing autoantibodies against IL-10 signalling components in patients with inflammatory bowel disease. BMC Immunology 2014 15:10.

\section{Submit your next manuscript to BioMed Central and take full advantage of:}

- Convenient online submission

- Thorough peer review

- No space constraints or color figure charges

- Immediate publication on acceptance

- Inclusion in PubMed, CAS, Scopus and Google Scholar

- Research which is freely available for redistribution

Submit your manuscript at www.biomedcentral.com/submit
C Biomed Central 